\title{
IKKUNAT KIINNI, SALPA OVELLE
}

\author{
PULKKINEN, MATTI: Romaani- \\ henkilön kuolema. Gummerus \\ 1985.
}

Valtakunnan poliittisen elämän keskiössä oli muutaman viikon ajan kirkkopyhien siirto. Tasavallan presidentti oli lykännyt lain voimaantuloa parilla vuodella, ja melkein ylittänyt valtuutensa (ylittikö todella? — siitä kiistellään vieläkin). Presidentti hermostui tästä niin, että haukkui hallituksen ja eduskunnan, ja varmemman vakuudeksi kansanedustajien vaalitavan. Presidentti sanoi kokevansa näin vaativien ratkaisujen tekemisen kovin raskaaksi.

Muutamaa kuukautta aiemmin oli julkaistu Matti Pulkkisen teos Romaanihenkilön kuolema. Ei näillä tapahtumilla ollut keskenään suoranaista tekemistä. Ajan myòtä kävi kuitenkin selväksi, että ne ilmensivät samaa aikakautta: Tasavallassa vedettiin miehissä verhoja ikkunoiden eteen.

Pulkkisen teos sai arvostelijoilta runsaasti kiitosta. Erityisesti ylistettiin teoksen rakenteellista ratkaisua. Pulkkinenhan kehitti kolmitasoisen kerrontarakenteen, palautettakoon se mieleen: Ensimmäisenà tasona olivat "kirjailijan" muistiinpanot - ne kattoivat vapaaehtoisen maanpaon Ruotsissa kotimaan jouduttua Neuvostoliiton painostuksen kohteeksi (mahdollisesti miehityksen? - tämà jäi lukijan arvailujen varaan), kokemuksia lapsuudesta Pohjois-Karjalassa ja nuoruudessa Etelä-Suomessa, sekä erityisen tärkeànä vaiheena matkan ItäAfrikkaan. Afrikan matkastaan "kirjailija" oli julkaissut romaanin, joka kaikesta päättȧen oli arvioitu rasistiseksi, koskapa "kirjailijan" muistiinpanot kảsittivät pitkän arvostelijoille, erityisesti tansanialaiselle Adoro Andurulle osoitetun vastauksen. Vastaus Adorolle kattoi Pulkkisen kirjasta lähes puolet ja oli sen sisällölle keskeinen.

Toisena tasona Pulkkisen kirjassa olivat "kirjailijan" ystävän "Makkosen" kommentit ja tulkinnat "kirjailijan" muistiinpanoista. "Makkonen" tunsi "kirjailijan" hyvin, koskapa osa tämän elämänkokemuksista tuli kronikoiduksi "Makkosen", kautta - siis ulkopuolisen kertojan äänellä.

Kolmantena tasona olivat "tosiasiat" - kokoelma läpi kirjan kulkevia yksityiskohtia, vàittämiä, ja rinnastuksia, jotka lukija tunnisti itseäàn (sekä "'kirjailijaa" ja 'Makkosta") ympäröivàn maailman piirteiksi. Nämä "tosiasiat" muodostuivat nekin kolmesta aineksesta. Vahvana juonteena olivat ensinnäkin "kirjailijan" suvun juuret, mm. isoisän Paavo Pulkkisen 1800-luvulla kirjoittamat raportit Pohjois-Karjalan taloudellisista oloista. Tähän osaan "tosiasioita" kuuluivat myös "kirjailijan" aikaisempien teosten $J a$ pesäpuu itki sekä Elämain herrat syntyvaiheiden tapahtumat. Toisen koosteen "tosiasiat" muodostivat Adoro-jaksoon kootut "kirjailijan" kokemukset Afrikasta seka tähản liittyvät tolvailevat arviot kolonialismin jälkeisestä Afrikasta ja kehitysavun mielekkyydestä. Edelleen "tosiasioiksi" lukeutuivat "kirjailijan" muistiinpanot Puolasta, Neuvostoliitosta, sekà Neuvostoliiton painostaman (vai miehittȧän?) Suomen kohtalosta.

Kirjansa kolminkertaisella rakenteella Pulkkinen toteutti uudenlaisen version brechtiläisestä vieraannuttamisesta. Brechtin eeppisessä teatterissa katsoja joutuu arkipàivän totuuksien kanssa vastatusten tavalla, joka pakottaa arvioimaan ne uudelleen: "Tosiasiat" paljastuvat kaikkea muuta kuin yksinkertaisen tosiksi. Pulkkisen kolmiportaikko johtaa painvastaiseen. Lukija seuraa, mitä "Makkonen" kertoo "kirjailijan" elamanvaiheista ja kokemuksista, ja ahaa-elamykseksi tuleekin: "tosiasiat" toden totta ovat tosia! Suomalaisilla, etenkin pohjoiskarjalaisilla, on ankara mutta kunniallinen historia! Afrikkalaiset ovat alkeellisia! Sosialistiset maat ovat kansojen vankiloita!

Brechtin katselija huomaa "tosiasiat" petollisiksi ja alkaa luottaa kokemukseensa ja arvostelukykyynsä. Pulkkisen lukija alkaa epäillà kokemustaan ja arvostelukykyảản ja jaä heitteille "tosiasioiden" hetteikköon.

Olihan tamả rakenteellinen hattutemppu kirjallisena ratkaisuna kiintoisa. Se merkitsi faktan ja fiktion rajan hämärtymistà kaunokirjalli- suudessa täysin toisella tavoin kuin historiallisiin tilanteisiin sijoitetuissa perinteisissä romaaneissa, kuten kriitikot riensivät toteamaan. Mutta perin harva kriitikko huomasi tảstä seuraavaa kysymystä: Mitä olivatkaan ne nimenomaiset yksityiskohdat, väittämät, ja kokemukset, jotka Pulkkisen vieraannuttamistekniikka muutti "tosiasioiksi"? Kun "tosiasiat" nivelletään kirjallisuuteen, on kirjallisuutta arvioitava myös noiden "tosiasioiden" kannalta. Tosiasia on häilyvá ilmiö, etenkin oltaessa tekemisissä sellaisen maailman kanssa, johon yksilon aistit eivät kanna. Nämä "tosiasiat" luetaan lehdistá, ja niiden hyväksymiseen tai hylkäämiseen eivàt yksityisen ihmisen kokemukset riitá. On kyseenalaista, voiko ihmiskuntaa laajemmin koskevia yhteiskunnallisia kysymyksiä ylimalkaan "nähdä" tai "kokea" — ne vol vain tiedostaa ja tajuta.

Tässä suhteessa yhteiskunnassa oli tapahtunut syvä murros, jonka Pulkkisen kirja toi esiin. Pulkkinen kirjasi kirjaansa prosessin, jonka tulosena yksilön elämànkaaren tuottamat hajanaiset kokemukset sekä "tosiasiat" niveltyvät kokonaisuudeksi (ei toki yhtenäiseksi). Siis maailmankatsomuksen. Ja yritti saada sen toistumaan lukijoidensa päissä.

Maailmankatsomus on useimmiten kestävä yksittaiisten asiaintilojen suhteen. Harvoin sitä valitaan "tosiasioiden" perusteella, pikemminkin "tosiasiat" seulotaan maailmankatsomuksen perusteella. Nainhän on laita empiirisısta empiirisimmissá luonnontieteissäkin — jo Eino Kaila eritteli terävästi "perseptuaalista" ja "konseptuaalista" ainesta, jotka kätkeytyvàt vảlittomien aistihavaintojen taustalle, antavat niille hahmon. ${ }^{1}$ Miten tàmä rinnastuu Iltalehden lukemiseen tai televisiouutisten katseluun?

Pulkkisen kirjan varsinainen sisalto siis oli maailmankatsomus. Se oli vieläpä vasta-maailmankatsomus. Suomessa oli 60-luvulla oivallettu, että maailmassa on muutakin kuin Suomi lähinaapureineen. Oli myös oivallettu, ettà maailma ei aina ole sellainen kuin mıltá se näyttáa. "Mikảli se olisi, ei tiedettà tarvittaisi", tavattiin erästä 1800-luvulla elà- 
nyttả ajattelijaa lainata. ${ }^{2}$ Tätà näkemysten avartumista kohtaan oli valtakunnan ylimmissä umpioissa tunnettu närää koko 70-luvun ajan. Sitten tuuli tuntui viimein kääntyvann. Kansallinen itse-ehostus koki vahvan nousun, ja kansalaisten muusta maailmasta tunteman huolen toivottiin viimein hälvenevän. Pulkkinen purjehti tukevassa myötätuulessa.

Jälkikäteen arvioiden Pulkkisen kirjan myötätuulisuus on päällekäyvää. Pulkkinen kirjoitti (esimerkik$\mathrm{si}^{3}$ ): "Mietin, miten säädyllisesti kirjoittaa Afrikasta. Sen verran maanosa oli minua opettanut, että Sara Lidmanin ja Andre Brinkin 'eläytymiset' mustiin henkilöihin vaikuttivat yhtä róyhkeän falskeilta kuin taistolaisrunoilijoiden eteläamerikkalainen kärsimysmystiikka; ja kun oli nähnyt Afrikan, ihmisten lisääntyvän ja kaluavan maan paljaaksi, ja sitten kuunteli suomalaisia kaiken hyvàn helppoheikkeja, jotka luulivat että on yksi maailma, jossa se mikä teki täällä ja heille hyvaá teki samaa muualla ja muille; ja miten pakkorauhaansa tukehtuva kansa jonka hysteriaa Moskova laskelmallisesti lietsoi, kuten Shevtshenkon muistelmista voivat lukea nekin jotka eivät usko kuin painettua sanaa, puhui, lauloi, lausui toinen toiselleen: 'Me tahdomme rauhaa!' - samanlainen lause kuin 'Me tahdomme onnea!' - ja kuvitteli astuvansa yhtä jalkaa yleissaksalaisen 'rauhan'-liikkeen kanssa, ikään kuin olisi yksi rauha, ja kaikilla kielillä sama; ja kun tässa tuonnin ja viennin varassa ajelehtivassa maassa seurasi sen kirjailijoita jotka kyykơttivät piirissà selät ulospain tikistảmässá suomalaisen kirjallisuuden mestariteoksia entisten päälle, romaaneja, piiloelämänkertoja joissa kirjailija henkilöidensà naamioasun alta vilauttaa lukıjan himokkaan silmän eteen milloin nilkkaansa milloin reittään, tuntui että selvittämista olisi tässákin, meissä, ilman ettà tahan sotkuun vielä kuvitellaan 'henkiloita' lisää.',

"Näin minäkin olen aina uskonut, vihdoin joku saa sen vaikuttamaan todelta", ajatteli moni Pulkkisen kirjaa lukiessaan. Kriitikot kertoivat, että Pulkkinen on rohkea ja omaperäinen.

Poliittinen krapula oli myótàtuu- lena Pulkkisen purjeita pullistelemassa. Tasavallassa oli 70-luvulla koetettu saada aikaan jotakin, mikä ei ollut onnistunut ja oli tullut muotiin tuntea siitä krapulaa. (Tosin on edelleen epáselvää, ketkä sitä varsinaisesti tunsivat. Sanomalehtien toimittajat ehkä? Sitäpaitsi näin jälkikäteenhän tiedämme, että 70-luvulla oli saatu aikaan paljon enemmän kuin tuolloin luultiin. Tekeminen tuottaa aina, joskin eniten olivat jälkeenpäin viisaita ne jotka eivat koskaan mitään yrittäneetkään. Tästä J.K.Paasikivi ${ }^{4}$ piruili, ja hảntä toisteltiin ahkerasti yhdessá, mutta ei toisessa yhteydessä.)

Ei se ollut ensimmäinen krapulasukupolvi, paitsi ehkä Suomessa, mutta poliittisen krapulan teema on toki mielenkiintoinen. Jännittävän rinnastuksen tarjoaa ensimmäisen ja toisen maailmansodan välisená aikana politisoitunut polvi, joka törmàsi vaikeisiin asioihin $40-$ ja 50 luvuilla. Esimerkiksi Lysenko sai monet radikaalit luonnontieteilijät sulkeutumaan takaisin laboratorioihinsa. Tosin joku Richard Levins ${ }^{5}$ kertoi 80 -luvulla poikamaisen jälkiviisaasti hymyillen kääntäneensä lukiolaisena Lysenkon artikkeleita englanniksi ja julkaisseensa niistä maksullisen mainoksen Science -lehdessa USA:ssa, juuri parahiksi McCarthyn nousun aikaan. Jalkiviisaus on sitá, että tietää tehneensä parhaan minkä ymmàrsi, ja oppineensa. Jalkityperyys on muuta.

Tunnetuin 40-luvun krapulisteista oli tietenkin George Orwell. On helppoa esittää Orwellin kehityskaari idealistisesta aktivistista Espanjan sodan turhauttavien kokemusten kautta kylmán sodan pessimistiksi kuin logiikan rautaisen kàden säätämäksi, mutta eihän asia niin yksinkertainen ole. ${ }^{6}$ Orwell kuitenkin kohosi muuriksi, jonka yli seuraavan sukupolven oli kiivettảvä. Tastä kiintoisa dokumentti: Orwell kirjoitti 30-luvulla esseen Inside the Whale, jossa julisti yksilöllisyyttä ja passiivisuutta senaikaisen kirjallisuuden tunnukseksi yhteiskunnallisen osallistumisen sijasta. Kun uusi radikaali sukupolvi nousi Englannissa esiin 60-luvun lopulla, eràs valttamattömyyksistä oli yhteenotto Orwellin kanssa. Ihmeteltiin, ettá lordi Russell oli maan ai- noa älyllisesti aktiivinen ja rehellinen intellektuelli Pommin aikakaudella. Irtauduttiin Orwellin perinnöstä: Riittää varpaiden kaivelu ja oman vatsan katselu! "Outside the Whale'!?

Pulkkisella oli yhtymäkohtia Orwelliin. Pulkkisenkin oli kokemusten karikoittama taivallus johtanut pessimismiin, jonka voi saada näyttảmáan vaistảmättömältá. Mutta toki enemmän on eroja. Orwell kykeni samanaikaisesti elàytymään ja ottamaan etaisyyttá, kokemaan ja arvioimaan; tảmähän oli etenkin hänen reportaašiproosalleen leimallista. Pulkkinen ei oikein kyennyt kumpaankaan. Kuin lukisi koostetta yleisönosastokirjoituksia - hyvin kirjoitettua, toki, mutta niinhän ne usein ovat.

Loppujen lopuksi poliittinen krapula on vaivalloinen myötäisen puhaltaja, koska se menee ohi. Näinhän kävi lopulta Suomessakin, sitten kun aikanaan huomattiin välttämättömäksi 70-luvun ideoihin ja teksteihin palaaminen ja niiden kriittinen ylittaminen. Pulkkinen kivistävine ohimoineen istui jälkijunassa.

Pulkkisen kirja oli tietenkin tärkeä oire ja eräs erityinen piirre on etta se ilmensi historian yksiaikaisuuden murtumista. Erityisesti Suomessa tamá oli kova kokemus. Olihan valtakunta 60 -luvulle asti ollut agraarinen, eıka ajan (saatikka historian) jásentyminen ollut suurelle osalle kansaa mikààn ongelma; murroksen kovuus heijastui Pulkkisen kirjan "kirjailijan" lapsuudenmuistoissakin. Myos 60-luvun henkinen avautuminen ja edistysusko olivat yksiaikaisia - ajateltiin maalman muuttuvan yhtenà suoraviivaisena ryöppyna. Tähản sisảltyi ratkaisematon ongelma, mikä sittemmin kostautui.

60-luvun edistyvän ja ongelmansa ratkaisevan maailman tilalle Pulkkinen loysi 80-luvulla jumissa seisovan maailman, jonka lukuisat ongelmat näyttajytyivàt yhteismitattomina ja enimmäkseen ratkaisemattomina. Tämä oli "kirjailijan" Afrikan kokemusten sanoma. Mutta näköharhastahan siinä oli kyse, kuten yksiviivaisen edistyksen ajatuksessakin - paljon vakavammasta vain. Kun Pulkkisen tekstiä oli luettu hiu- 
kan tarkemmin, ensimmäisen hämmennyksen hälvettyä, siitä paljastui kaksi perustavaa epäloogisuutta.

Miten, ensiksikin, Afrikka oli juuri nyt auttamattoman kaaoksen edessä, kolme vuosikymmentä siirtomaavallan sortumisen jälkeen? Vain kolme vuosikymmentä! Millaisina afrikkalaisten näköalat olisivat ilmenneet kolme vuosikymmentä aikaisemmin? Vain kolme vuosikymmentä!

Tietenkin eräs suoraviivaisen edistysuskon harhoista oli ollut kuvitelma, että kolonialismin seuraukset voi kivuttomasti raivata syrjään. Eihän se niin helppoa ollut (eihän se ole vieläkään!) - tulihan monissa maissa siirtomaavallan tilalle voitonpyytöinen uudis-yläluokka korruptioineen ja valtataisteluineen. Pulkkinen vain ei pohtinut, mikä oli teollisuusmaiden osuus tässä kehityksessä. (Ei tätä tosin pitänytkään pohtia aikana, jolloin tasavallan kehitysavun ohjenuoraksi oltiin ottamassa normaaleja kaupankäynnin ja voiton periaatteita. Mutta se Pulkkisen rohkeudesta.)

Sahelin alueen nälänhädät kutoivat karulla tavallaan yhteen syiden ja seurausten lankoja Pulkkisen "kirjailijan" Afrikan-matkailun aikoihin. "Kirjailija" totesi, kuin paljastuksena, että monissa Sahelin alueen maissa oli nälänhädän aikana runsaat ravintovarastot, joita ei vain jaettu väestölle. Tämähän oli käynyt ilmi maailman elintarviketuotannon ja kaupan tilastoistakin: Nälänhädän aikana useimmat Sahelin alueen maat olivat maataloustuotteiden nettoviejiä. Mutta vientilistalla olivat maapähkinät, puuvilla, kaakao, . . ., eivätkä viejiä tarkkaan ottaen olleet Sahelin maat, vielä vähemmän Sahelin asukkaat, vaan Unilever ja ranskalaiset agribusineksen yhtiöt, joiden erityisasema alueella periytyi Ranskan siirtomaavallan ajoista. Millä kuivuusalueen paimentolaiset ostaisivat maapähkinöitä (ja mitä he tekisivät maapähkinöillä), olipa nälänhätà tai ei?

Toiseksi, Pulkkinen onnistui kirjassaan tulkitsemaan historian hajaantumista, mutta eihän tämä merkinnyt että historia loppuu. Asiat seurasivat edelleen toisiaan, vain eriytyneempinä. Tähän liittyi jännit- tävä paradoksi: Yksittaiset asiat saivat lisää painoa, kun niitä ei enäà tarvinnut liimata yhteen maailmanhistorian suureen palapeliin. Asiat eriytyivät - ja monet panivat merkille, etta eriytyneisiin asioihin voi vaikuttaa, vieläpä ratkaisevasti. Pulkkisen kirjan "kirjailija" piti sietämättömänä naivismina sitä, että jotkut Suomessa puhuivat Sabran ja Shatilan verilöylyistä samaan aikaan kun Afrikassa riehui sisallissota. Ei se naiivia ollut. Eriytyneessä maailmassa yksittäistapaukset muuttuivat symboleiksi, joiden merkitys osoittautui sittemmin arvaamattomaksi. Vieläkin puhutaan, esimerkiksi, luonnonsuojelun aktivistien keskuudessa ajasta ennen Rainbow Warrioria ja ajasta Rainbow Warriorin jälkeen. Yllättävän nopeastihan toteutui myös se, että ajatus sisällissodasta Ugandassa tai Malawissa tuntui yhtä mielettömảltä kuin ajatus sisällissodasta Englannissa tai Ranskassa (ei sen puoleen laisinkaan mieletön ajatus kovin pitkään ennen Pulkkisen aikaa).

Sanalla sanoen, Pulkkisen kirjan ilmentämä maailmankatsomus joutui piankin kritiikin kohteeksi. Ensiksi: Voi olla, että maailma on mieletön ja ongelmat ratkaisemattomia - mutta jos kaikki yhtyvät tähän, niin ne varmasti ovat. Toiseksi: Historia ei ole yhtenäinen edistyvä prosessi, hyvä on. Mitä tästä seuraa? Se, että vapaudutaan miettimään asioiden spesifejä merkityksiä ja tekemisten spesifejä seurauksia yleisten (historiallisten) merkitysten ja seurausten sijasta. Eriytyneessä maailmassa pienillä asioilla voi olla suuria vaikutuksia.

Näin jälkikäteen voi arvioida, että tekeminen muuttui utopistisemmaksi ja realistisemmaksi samanaikaisesti. Menneiden päivien krapulat haihtuivat kuten krapulat yleensäkin, ja tasavallassa hätkähdettiin jälleen liikkeelle: Maailmassa joudumme elämään ja toimimaan, eläkäämme ja toimikaamme siis!

Mutta tämä menee jo ohi Pulkkisen kirjan, sillä Pulkkisen sanoma oli päinvastainen: Kaihtimet alas lattianrajaa myöten, ikkunaluukut ja ovet sisäpuolelta salpaan.

\section{Viitteet:}

1. Eino Kaila, suomalainen filosofi; viitataan hänen esseeseensä Aistikokemuksen perseptuaalinen ja konseptuaalinen aines vuodelta 1956.

2. Tarkoittanee Karl Marxia.

3. Romaanihenkilon kuolema ss. 609-610.

4. J.K. Paasikivi, pankinjohtaja ja tasavallan presidentti $(1940 / 50-$ luvuilla); hänen päiväkirjamerkintöjään oli julkaistu Pulkkisen kirjan ilmestymisen aikoihin, ja niiden jokaista puolipistettä ja tavuviivaa tutkittiin suurella hartaudella.

5. Richard Levins, yhdysvaltalainen radikaali biologi; vieraili Suomessa 80-luvulla, haastattelu julkaistu Tiede \& Edistyksen numerossa $1 / 83$.

6. Luonnonvälttämättömyys-näkemystä heijastaa esimerkiksi Orwellin standardibiografia Bernard Crick: George Orwell. A Life (Penguin Books); vivahteikkaamman tulkinnan on esittänyt Raymond Williams: $O r$ well (Fontana Paperbacks).

7. Outside the Whale, historioitsija E.P. Thompsonin vuonna 1960 kirjoittaman esseen otsikko (julkaistu alunperin hänen toimittamassaan kokoelmassa Out of Apathy). 